$18 \%$ were against this strategy. Only $44 \%$ reported having sufficient knowledge about the use of HPV vaccine for MSM and $49 \%$ reported having skills to identify MSM likely to benefit from HPV vaccination. While 19\% agreed that it is too late to offer HPV vaccine to sexually active MSM, 53\% thought all MSM, regardless of their age, should be offered the vaccine. Conclusion SHCPs perceived the need to vaccinate MSM against HPV. Despite insufficient knowledge, a gender-neutral HPV vaccination strategy was favoured over targeted HPV vaccination for MSM. Clear advice and guidelines for SHCPs on HPV vaccine use in men at sexual health clinics are required to ensure equitable opportunities for vaccination. If MSM-targeted HPV vaccination is recommended, SHCPs' attitudes need to be taken into account to achieve optimal uptake.

\section{P106 HOW SHOULD PATIENTS BE CALLED FROM THE WAITING AREA WHEN ATTENDING FOR SEXUAL HEALTH SERVICES? A SERVICE EVALUATION}

${ }^{1}$ Emma Dorothy Mills*, ${ }^{2}$ Steve Baguley. ${ }^{1}$ University of Aberdeen, School of Medicine and Dentistry, Aberdeen, UK; ${ }^{2}$ Genitourinary Medicine, NHS Grampian, Aberdeen, UK

\subsection{6/sextrans-2015-052126.149}

Background/introduction The initial encounter between health professional and patient is fundamental to establishing rapport. It is important in a sexual health setting that patients feel at ease with however they are identified in the waiting area. Recent research suggested patients with HIV preferred to be identified by first name whereas most others preferred a number, and all patients in these categories should be called in these ways.

Aim(s)/objectives To determine the proportion of patients who expressed a preference to how they were called from the waiting room. And, to determine whether there was any association with reason for attendance, age, gender or HIV status.

Methods 167 patients who attended a drop-in clinic in October 2014 and 50 patients with HIV who had recently attended for HIV care were identified and included. Pearson's Chi-Squared Test was used to analyse the relationship between calling preference and sex, reason for attendance, and age (based on the median age of 26). When assumptions were not met, Fisher's exact test was used.

Results $60.8 \%(\mathrm{n}=132)$ of patients expressed no preference as to how they would like to be called from the waiting area. $36.4 \%$ requested their real details be used, $2.8 \%$ requested false details be used $(n=6)$. There was no statistical significance found between reason for attendance and preference $(\mathrm{p}=$ $0.406)$, age and sex did not significantly influence preference $(\mathrm{p}=0.172, \mathrm{p}=0.288)$.

Discussion/conclusion The results suggest offering every patient the choice of how they wish to be addressed would be the most appropriate method used to call patients from the waiting area.

\section{P107 SEXUAL HEALTH SERVICES FOR MEN WHO HAVE SEX WITH MEN (MSM): ARE THEY ACCEPTABLE?}

${ }^{1}$ Thomas Kurka*, ${ }^{2}$ Suneeta Soni, ${ }^{2}$ Daniel Richardson. 'Brighton and Sussex Medical School, Brighton, UK; ${ }^{2}$ Brighton and Sussex University Hospitals NHS Trust, Brighton, UK

\subsection{6/sextrans-2015-052126.150}

Background/introduction Locally, there is a large population of MSM. MSM have high and increasing rates of STIs and HIV: sexual health services should be accessible and MSM focussed.
Aim(s)/objectives The aims of this study were to assess patients' satisfaction with the current services, preferences on staff gender, preferences on self-taken rectal and throat swabs, and the need for a specialist MSM service.

Methods Patient satisfaction survey of MSM attending four MSM-services in our city (hospital-based STI clinic and HIV clinic, a local non-government organisation (Terence Higgins Trust) and a walk-in primary care centre). Data were analysed using SPSS.

Results 246 MSM completed surveys between January-March 2014. The median age was 35 years (18-79). Most MSM $(92.3 \%)$ self-identified as gay, $7.3 \%$ as bisexual and $0.4 \%$ as other. $12.7 \%$ self-identified as HIV-positive, 61.1\% HIV-negative, 20.0\% unsure and 5.7\% never tested. 206/246 (83.7\%) did not have a staff gender preference, the male: female staff preference was 35:5/246 (14.2\%:2.0\%). 113/227 (49.8\%) would welcome self-taken rectal/throat swabs. 101/232 (43.5\%) would prefer to be seen in a specialist MSM service. Overall, there was no significant difference in preference between HIV-positive and HIV-negative/unsure/never tested. The overall satisfaction with reception staff was $95.5 \%$ (outstanding/good) and 99.1\% with doctor/nurse (outstanding/good).

Discussion/conclusion Overall, there is high satisfaction with sexual health services currently provided to MSM locally. Most patients do not have a staff gender preference but almost half of MSM would prefer a specialist service. We concluded that offering self-taken rectal and throat swabs would be acceptable for many MSM patients.

\section{P108 HOW DO MEN WHO HAVE SEX WITH MEN FARE IN INTEGRATED SEXUAL HEALTH CENTRES? AN AUDIT OF HEPATITIS B VACCINATION RATES BEFORE AND AFTER INTEGRATION}

Sally Wielding*, Andy Ma, Dan Clutterbuck. Chalmers Centre, NHS Lothian, Edinburgh, UK

\subsection{6/sextrans-2015-052126.151}

Introduction In Scotland, Health Improvement Scotland (HIS) standards require that $70 \%$ of men who have sex with men (MSM) attending specialist sexual health services who are not known to already be immune should receive at least one dose of hepatitis B vaccine. The integration of sexual health services could theoretically disadvantage MSM.

Objectives Audit was performed before and after integration of genitourinary medicine (GUM) and sexual and reproductive health (SRH) services in April 2011 to assess the impact of service redesign.

Methods HBV vaccination eligibility, uptake and course completion by MSM registering as new patients in general sexual health and specialist MSM clinics was audited retrospectively for 6 month periods before and after integration of services.

Results Pre-integration 239 MSM registered for a first episode of care: $62.8 \%$ were eligible for vaccination. Post-integration $25.3 \%$ of 343 new patients were eligible. The proportion of eligible men receiving at least 1 dose of vaccination pre- and post-integration was unchanged $(130 / 150=86.7 \%$ vs $78 / 87=$ $89.7 \%, \mathrm{p}=0.6458, \mathrm{Chi}^{2} 0.2223043$ ) However, there was a significant reduction in the proportion of men receiving 3 doses of vaccination; $(76 / 150=50.7 \%$ vs $30 / 87=34.5 \%, p=0.0157$, $\mathrm{Chi}^{2}$ 5.834).

Discussion SRH services continued to provide very high levels of initiation of $\mathrm{HBV}$ vaccination, even during the period 
immediately after integration when clinic accommodation, pathways and staffing were in a state of change. The reduced completion rates of a 3-dose course post-integration suggest that clinic access, availability and acceptability for MSM as well as recall arrangements should be explored.

\section{P109 "LOVE THY NEIGHBOUR": AN EVALUATION OF RELIGION AS A POTENTIAL BARRIER TO ACCESSING SEXUAL HEALTH SERVICES FOR GAY AND BISEXUAL MEN IN THE WEST OF SCOTLAND}

Elizabeth Rooney*, Diane Willis. University of Glasgow, Glasgow, UK

\subsection{6/sextrans-2015-052126.152}

Background/introduction Outcome 5 of the Blood Bourne Virus Framework aims for a society where attitudes towards sexual health and HIV are supportive and non-stigmatising. Currently, there is no research as to whether religion is a barrier to attending sexual health services for gay and bisexual men.

Aim(s)/objectives To explore the influence of religion and its relationship to sexuality for gay and bisexual men. To explore if religious beliefs affect attendance at sexual health services and whether current standards of care at sexual health services meet their needs.

Methods Nine participants participated in semi-structured interviews; five sexual health staff; four non-NHS staff including three ordained Ministers from different religions. Questions were about their views around the influence of religious beliefs on the sexual health of gay and bisexual men in the West of Scotland.

Results Four themes were identified: barriers to attending sexual health services, influences of religion/coping behaviour, societal influences and provision of sexual health services. Seven of the nine participants identified that religion is a potential barrier to attending sexual health services. Potential conflict between faith and sexuality affect health seeking behaviour. Implications for practice included staff training, outreach work and referral to Chaplains.

Discussion/conclusion This study finds that religion is a potential barrier to attending sexual health services for gay and bisexual men, particularly if their religion and sexuality are in conflict. It can be linked to risk taking behaviour and stigma is a considerable issue. Recommendations were made for improvements in service provision. Further research is required.

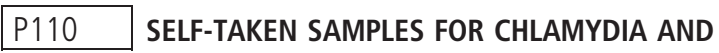 GONORRHOEA IN HIV OUTPATIENTS ARE ACCEPTABLE AND PERCEIVED AS RELIABLE AND COMFORTABLE BY PATIENTS}

Adam Croucher*, Tracey Buckingham, Daniel Richardson. Lawson Unit, Royal Sussex County Hospital, Brighton, UK

\subsection{6/sextrans-2015-052126.153}

Introduction Self-taken samples increase testing for Chlamydia and Gonorrhoea in high-risk asymptomatic populations including HIV-outpatients. Women are offered self-taken vaginal samples; heterosexual men first-pass urine and MSM self-taken rectal and throat samples and first-pass urine. The acceptability of this method of testing is not well understood.
Methods An anonymous paper survey was offered to all patients attending outpatient-HIV clinic June-July 2014. Data collected: age, gender, ethnicity, sexual-orientation; perceptions of selftaken samples; whether they tested that day, and why.

Results 121 surveys were returned. Median age $=45(20-69)$ years; $86 \%$ male; $68 \%$ white British; 73\% homosexual. 61/121 $(50 \%)$ rated STI screening as 'very important', 48/121(39\%) as 'worthwhile': 117/121(96\%) rated offering self-taken samples in routine HIV clinic as appropriate. 86/121(71\%) found the instructions 'easy' to follow and 4/121(3\%) 'difficult'. 78/121 $(64 \%)$ said that they thought that self-taken samples are as reliable compared to clinician-taken and 10/121(8\%) thought they were more reliable. 60/121(50\%) said self-taken samples were as comfortable as clinician-taken; 30/121(25\%) said more comfortable. 33/121(27\%) responders did self-sampling that day; 78/121 (64\%) did not. Participants' reasons for accepting self-taken samples included: 'It's easier/quicker than going to a GUM clinic' (37\%); 'I prefer doing the swabs myself' (25\%). Reasons for not self-sampling included: 'I haven't had any sex since my last sexual health screen' (26\%); 'I was not offered a STI screen today' (20\%); 'I prefer to go to a GUM clinic' (16\%).

Conclusions The self-swab STI screens are acceptable to patients attending HIV outpatients', and are perceived as being as reliable and as comfortable as clinician-taken samples.

\section{P111 DISPERSAL OF A HIV COHORT FOLLOWING THE CLOSURE OF AN OUTREACH CLINIC NECESSITATED BY GOVERNMENT NHS RESTRUCTURING}

Noel B Connolly*, Jonathan Shaw, Justine Mellor, Orla McQuillan. Manchester Centre for Sexual Health, The Hathersage Centre, Manchester Royal Infirmary, 280 Upper Brook Street, Manchester, M13 OFH, UK

\subsection{6/sextrans-2015-052126.154}

Introduction Coalition government health policy has necessitated NHS restructuring. Sexual health provision was opened to competitive tendering with responsibility transferring to local authorities. BASHH/BHIVA published standards and it was expected local sexual health strategy agreements would continue. Methods DGH genitourinary care was provided by university hospital consultants since 2006 facilitated by the local sexual health network, HIV care wasn't due to funding restrictions. To improve care/retention, hub-and-spoke outreach was established in 2011 for $45 \mathrm{HIV}+$ individuals - 1/3 DGH diagnosed, 1/3 transferring from the larger centre, $1 / 3$ from other clinics. Nine (20\%) had previously disengaged. When tendering opened the local authority made no provision to maintain this service.

Results After awarding the tender to a community trust it became apparent that qualified staff would not be available to continue care of the cohort therefore it was maintained by the previous trust. Due to service fragmentation no new local referrals were made. Despite excellent feedback we reluctantly closed as continuing the spoke service became economically unviable. Patients were offered remaining with the same team at the teaching hospital (51\%), transfer to another clinic locally $(20 \%)$ or nationally $(15.5 \%)$ with some moving overseas $(4.5 \%)$. Of concern $4(9 \%)$ are presumed to have disengaged. Several complaints were raised at local authority level.

Discussion Despite upheavals patients must remain at the centre of NHS care. We found BASHH support helpful and suggest dissemination of our experience to others. Highly regarded and well-functioning services are not immune to change and an uncertain future may be expected. 